\title{
A FILOSOFIA PRÁTICA DE KANT: NOTAS SOBRE VONTADE E MORALIDADE NA FUNDAMENTAÇÃO DA METAFÍSICA DOS COSTUMES ${ }^{1}$
}

\author{
THE PRACTICAL PHILOSOPHY OF KANT: NOTES ON WILL \\ AND MORALITY IN GROUNDWORK OF THE METAPHYSICS OF \\ MORALS
}

\author{
Wécio Pinheiro Araújo* \\ Recebido: 10/2017 \\ Aprovado: 11/2017
}

\begin{abstract}
Resumo: O objetivo dessas notas não é trazer uma elaboração original, mas contribuir para o esclarecimento daqueles estudiosos de filosofia que começam a frequentar o texto kantiano. O corpus desta análise se concentra na Crítica da Razão Pura (Kritik der reinen Vernunft) e na Fundamentação da Metafísica dos Costumes (Grundlegung zur Metaphysik der Sitten). Entrecruzamos as obras supracitadas para demonstrar como Kant pensa a questão da liberdade buscando esclarecer racionalmente os princípios do fundamento moral a priori, isto é, em conceitos da razão pura sob juízos analíticos. Sendo isto possível somente a partir de uma rigorosa reformulação da metafísica.

Palavras-chave: Kant. Filosofia prática. Liberdade. Vontade. Moralidade.
\end{abstract}

\begin{abstract}
The purpose of these notes is not to bring an original, but to contribute to the clarification of those scholars of philosophy who begin to frequent the Kantian text. The corpus of this analysis focuses on the Critique of Pure Reason (Kritik der reinen Vernunft) and on the Groundwork of Custom Metaphysics (Grundlegung zur Metaphysik der Sitten). We interweave the aforementioned works to demonstrate how Kant thinks the question of freedom by seeking to rationally clarify the principles of a priori moral foundation, that is, in concepts of pure reason under analytical judgments. This being possible only from a rigorous reformulation of metaphysics.
\end{abstract}

Keywords: Kant. Practical Philosophy. Freedom. Will. Morality.

\section{Prolegômenos}

Uma coisa é conhecer a virtude, e outra é conformar a vontade com ela (HUME, 2001, p. 505).

"O maior mérito de Kant" e sua valiosa contribuição à filosofia, conforme apontou Schopenhauer, "é a distinção entre o fenômeno e a coisa-em-si"; isto é, a distinção entre o mundo real e o mundo fenomenal, "com base na demonstração de que, entre as coisas e nós, está sempre ainda o intelecto" (1999, p. 120). Ainda em 1770, por ocasião da sua aula inaugural na cátedra de Lógica e Metafísica da Universidade de Königsberg - escrita em latim e intitulada De mundis sensibilis atque intelligibilis forma et principii ("Sobre a forma e os princípios do mundo sensível e inteligível") ${ }^{2}$ - Kant já estabelecia as bases sobre as quais desenvolveria o seu pensamento filosófico, que acabou por torna-lo um

\footnotetext{
* Professor Adjunto da Universidade Federal da Paraíba (Campus I). Bolsista CAPES/PDSE 2017 Processo $\mathrm{n}^{\circ}$. 88881.133482/2016-01. Doutorando no Programa Integrado de Pós-Graduação em Filosofia (UFPB/UFPE/UFRN) com estágio sanduíche na Hochschule für Grafik und Buchkunst (HGB/Leipzig/Alemanha). Membro do Grupo Eule de Estudos em Filosofia e Crítica Social (DGP/CNPQ). E-mail: weciop@bol.com.br

Problemata: R. Intern. Fil. v. 8. n. 3 (2017), p. 69-77 ISSN 2236-8612 doi:http://dx.doi.org/10.7443/problemata.v8i3.37242
} 
dos mais influentes pensadores de todos os tempos. Segundo Ivan Buchanan, em seu Dictionary of Critical Theory ${ }^{3}$, sua influência contemporânea é tão grandiosa que, não raro, em inúmeras referências históricas, a filosofia europeia aparece dividida entre as escolas de pensamento pré e pós-kantiana.

No período que sucedeu sua nomeação como professor de Lógica e Metafísica, após o sobressalto ${ }^{4}$ ao dar-se conta da força do empirismo de David Hume com seu devastador ataque ao racionalismo dogmático, "Kant enfrentou então um dilema: ou ele aceitava o empirismo, junto com o ceticismo e o determinismo que derivavam dele, ou ele tinha que desenvolver uma nova e radical alternativa filosófica" (DUDLEY, 2013, p. 25); mas como aceitar a falência do racionalismo sem se deixar vencer pelo empirismo e seus efeitos? Respeitados comentadores, a exemplo de Will Dudley ${ }^{5}$ demonstram como claramente Kant estava preocupado em reagir "ao rude despertar de seu confortável sono dogmático tentando responder a Hume de uma maneira que preservasse a perspectiva da cognição racional, agir moral e liberdade política" (Ibidem). Lembre-se que ainda em 1739, Hume havia provocado toda tradição racionalista, sobretudo grandes nomes como Descartes, Espinosa e Leibniz segue trecho em sequência à nossa proposital epígrafe: "Portanto, para provar que que os critérios do certo e do errado são leis eternas, obrigatórias para toda mente racional, não basta mostrar as relações que os fundamentam; temos de mostrar também a conexão entre a relação e a vontade [...]" (Hume, 2001, p. 505, itálico do original). Julgamos que Kant aceitou o desafio, e reagiu empreendendo um exame crítico da própria racionalidade, afrontada por Hume. De acordo com Dudley (2013, p. 26), o projeto de crítica da razão iniciado por Kant terá como objetivo central "oferecer a defesa da liberdade e da moralidade, e assim fazendo preservar a perspectiva do iluminismo e da modernidade".

\section{A crítica da razão pura}

Ich kenne nichts Ärmer's Unter der Sonn' als Götter Goethe (Prometheus) ${ }^{8}$

Em 1781, cerca de uma década depois daquele sobressalto humeano, ele apresenta sua teoria do conhecimento formulada na Crítica da Razão Pura (Kritik der reinen Vernunft), na qual propõe desde o tópico introdutório intitulado $D a$ diferenciação entre o conhecimento puro e empírico, a seguinte questão: "Não há dúvida de que todo conhecimento começa com a experiência [...], nem por isso se origina todo ele da experiência" (KANT, 1974, p. 24). Assim inicia sua análise, para em seguida provocar com a indagação: “...existe um conhecimento 
independente da experiência e inclusive de todas as impressões dos sentidos?" (Ibidem). Nosso filósofo não hesita em defender que sim; e qualifica: "Tais conhecimentos denominam-se a priori" (Ibidem). Ou seja, Kant se refere àquele conhecimento no qual não se mescla nada de empírico, mas que figura depurado de toda experiência. Logo conclui que toda ciência racional deve dispor de princípios gerais a priori, independentes de contingências e eventualidades, ao que denominará de razão pura, mas sem deixar de reconhecer os limites e possibilidades de sua aplicação. Assim, Kant confere uma nova roupagem à metafísica 9 , refundando-a, agora como uma filosofia pura voltada a determinados objetos do entendimento, mas cujos postulados se apoiam em princípios a priori e apodíticos.

Após distinguir o conhecimento puro do conhecimento empírico, prossegue buscando mais uma distinção fundamental: entre o juízo analítico e o juízo sintético, atribuindo a este último, predicados acrescentados ao sujeito a partir da experiência; enquanto que no primeiro a conexão entre sujeito e predicado ocorre por identidade, sem sair do próprio conceito, e portanto, sem necessidade de recorrer ao testemunho da experiência (KANT, 1974, p. 27). Desse modo, ele estabelece os limites e possibilidades da metafísica como idealidade transcendental.

Kant chega então aquilo que nomeia de legislação da razão humana leia-se: a filosofia pura -, que abrange tanto as leis naturais como as leis morais. Das leis naturais se ocupará a filosofia da natureza, dirigindo-se "a tudo que é" - palavras do próprio Kant. Enquanto que das leis morais se encarregará a filosofia dos costumes, voltada "somente ao que deve ser" (KANT, 1974, p. 27). Seja como exercício propedêutico no estabelecimento de princípios a priori, seja no encadeamento sistemático de conhecimentos filosóficos mais elaborados, Kant nomeia sua filosofia pura de metafísica, conforme qualificamos. Por sua vez, a divide em, de um lado: metafísica especulativa, referente aos princípios relativos ao conhecimento teórico puro acerca de todas as coisas; e, por outro, a metafísica dos costumes, aquela referente aos princípios que determinam a priori e tornam necessários "o fazer e o não fazer" (Ibidem). Sendo assim, a metafísica dos costumes tratará propriamente da moralidade pura.

No entanto, ele não se fechará completamente nas especulações teóricas da razão pura, posto que não deixará de dar importância às necessidades práticas sob a realidade do senso moral, ou seja, de uma filosofia pura capaz de lidar com objetos do entendimento prático ${ }^{10}$, porém, sem recorrer a qualquer experiência, mantendo assim, a depuração do empírico voltada para o pensamento a priori, só que dessa vez dirigindo-se ao campo da moral; só que no sentido preciso de valor moral, posto que "não é das ações visíveis que se trata, mas dos seus princípios íntimos que não se veem” (KANT, 1974, p. 213). 
Eis o nascedouro de uma Crítica da Razão Pura Prática enquanto caminho que Kant irá vislumbrar para se chegar a uma Metafísica dos Costumes posteriormente, e prometida já desde as seções finais da sua Crítica da Razão Pura. Cabe salientar que Kant justifica a necessidade de uma Metafísica dos Costumes não apenas em motivos de ordem especulativa, mas sobretudo na preocupação de que os próprios costumes possam sofrer "toda sorte de perversão caso Ihes falte uma norma suprema de seu exato julgamento" (KANT, 1974 , p. 199) - palavras que contraditoriamente parecem denunciar ainda alguma influência da sua formação passada na doutrina pietista.

Entrementes, sob a declarada intenção, que já aparecia nas conclusões de sua Crítica da Razão Pura, de um dia publicar sua Metafísica dos Costumes, alguns anos mais tarde Kant Ihe fará preceder a sua Fundamentação (1785) este último texto, sobre o qual nos debruçamos aqui.

\section{A Fundamentação da Metafísica dos Costumes}

O impulso transforma-se em desejo, o desejo domina a vontade, esta assume o caráter de um anseio incontrolável e o anseio ([...], apesar de todas as possiveis consequências) é imediatamente satisfeito (ALLAN POE, 2016, p. 5, 6).

Na então Fundamentação da Metafísica dos Costumes (Grundlegung zur Metaphysik der Sitten), Kant busca princípios morais a priori que permitam produzir uma vontade boa em si mesma, à medida que fornece uma norma suprema de moralidade ao ser humano como fundamento da obrigação enquanto necessidade absoluta de agir racionalmente segundo leis morais concebidas de maneira apodítica. Com isso, ele não pretende ensinar ou prescrever regras morais, mas esclarecer racionalmente os princípios do fundamento moral a priori, isto é, em conceitos da razão pura sob juízos analíticos, conforme desenhados na sua Crítica da Razão Pura - e assim como sinalizamos; o que constitui por si só uma tarefa bem distinta de qualquer investigação moral no campo da vida prática propriamente dita. Neste caso, Kant insiste que cair em princípios apoiados na experiência, ou seja, na regra prática, seria distanciar-se de alcançar seu objetivo maior que é estabelecer uma filosofia da moral capaz de fornecer princípios apriorísticos de uma moralidade pura.

Para Kant, a vontade de satisfazer um desejo egoísta brota do impulso instintivo e irracional, enquanto a vontade de obedecer à razão requer um motivo racional. Logo, para ele, a liberdade consiste em não sucumbir aos impulsos irracionais, mas, por meio da razão como conhecimento filosófico puro, superar qualquer ideia vulgar do dever e das leis morais. Para isso, a lei moral deve trazer consigo uma necessidade absoluta como fundamento do dever em si 
mesmo; fundamento este que não deve ser buscado na contingência da experiência humana ou nas circunstâncias do mundo no qual está situado o ser humano. Mas, ao contrário, deve ser procurado em princípios da vontade livre de toda motivação empírica, ou seja, como vontade pura. E essa vontade não poderá ser boa por meio daquilo que promove ou realiza, mas tão somente pelo querer em si mesma, e considerada como boa vontade em si mesma.

Neste contexto, junto com o princípio da boa vontade supramencionado, surge a questão do dever. Segundo Kant, para a máxima de uma ação valer como lei moral terá que ser praticada "por dever", e não "conforme o dever" (Kant, 1974, p. 208). Desse modo, o valor moral da ação não reside no que dela se espera ou no propósito que com ela se possa atingir - seja do que se possa ganhar ou não perder no cumprimento do dever -, mas, ao contrário, o seu valor moral se estabelece pelo próprio princípio que a determina a priori enquanto fundamento da moralidade em si mesma. Assim como também necessidade absoluta de respeito a lei moral sob rigorosa universalidade; pelo que Kant arrematará com o imperativo categórico enquanto "uma lei universal das ações que possa servir de único princípio à vontade" (Kant, 1974, p. 209). A passagem do conhecimento vulgar ao conhecimento filosófico - na primeira seção da Fundamentação da Metafísica dos Costumes - se dá justamente nessa capacidade de se elevar da dimensão egoístico-passional ao patamar das leis morais universais, assim como resume Kant: "devo proceder sempre de maneira que eu possa querer que a minha máxima se torne uma lei universal" (Ibidem).

Por conseguinte, através da pura representação do dever e da lei moral no conhecimento filosófico, chega-se à possibilidade de fundar os costumes sob seus autênticos princípios, assim como também de criar disposições morais universais, no lugar de seu uso vulgar e utilitário; tal possibilidade é encontrada nesta própria metafísica dos costumes alcançada ao ponto que da faculdade prática da razão pura brota o conceito do dever a partir de determinações de uma vontade pura em si mesma.

Logo, a vontade para Kant manifesta-se como a razão prática e a capacidade de agir segundo determinações das leis morais universais - ou seja, guiada por estas. No entanto, Kant alerta que a vontade pode sucumbir à contingência, tanto no plano das ações objetivas, como no plano subjetivo. Assim, a determinação da dever segundo o mandamento da razão pura é o que se manifesta como obrigação para a vontade. Chegamos então ao imperativo como a fórmula desse mandamento. Este, de uma lado, pode representar a necessidade prática de uma ação como meio de alcançar outra coisa do querer; o que Kant designará como imperativo hipotético. E por outro lado, quando representa uma ação objetivamente necessária em si mesma, independente de qualquer outro fim ou interesse, teremos o imperativo categórico. Desse modo, 
todos os imperativos são formas de determinação da ação que é necessária; porém, quando a ação é necessária como meio para alguma coisa, o imperativo é hipotético, mas quando a ação é uma vontade em si conforme um princípio apodítico prático da lei moral universal, o imperativo é categórico - este último é o autêntico imperativo da moralidade na Fundamentação da Metafísica dos Costumes, a saber: "age segundo a máxima que por si só possa ser uma lei universal" (Kant, 1974, p. 235). Neste sentido, a lei moral se põe como conceito de necessidade objetiva, incondicionada e de aspiração universal. Essa aspiração da vontade segundo a determinação pura da razão é o que Kant denominou de filosofia prática. Nesta última, "A moralidade é pois a relação das ações com a autonomia da vontade, isto é, com a legislação universal possível por meio de suas máximas" (Kant, 1974, 238). Vejamos a seguir.

O imperativo categórico como princípio objetivo e apriorístico da vontade pura que serve de lei moral universal, representa a vontade como legisladora em si mesma, e que não sucumbe a um interesse qualquer, nem pode ser extraída da experiência. Para se tornar prático, o imperativo categórico, segundo Kant, deve ser relido assim: "Age de tal maneira que uses a humanidade, tanto na tua pessoa como na de qualquer outro, sempre e simultaneamente como um fim, e nunca simplesmente como meio" (Kant, 1974, p. 229). Esta releitura do imperativo categórico como um imperativo prático significa a possibilidade da passagem de uma filosofia moral contingente para a condição fundamental da sua metafísica dos costumes, na qual o imperativo categórico se consolida como autonomia da vontade pura e princípio supremo de moralidade.

E mais: essa autonomia só poderá ser alcançada se a vontade busca a lei que deve determina-la em si mesma, como necessidade absoluta enquanto fundamento do dever independente dos objetos da experiência, estando obviamente, em oposição com o imperativo hipotético, que gera a heteronomia. Esta última, deve ser entendida como quando a vontade procura a lei que determinará sua ação necessária fora dos seus princípios apodíticos, isto é, em objetos do desejo e das paixões que a levarão a fazer algo com propósito em alguma outra coisa. Neste caso, na medida que o desejo determina a vontade se tornando sua lei, é que Kant apontará a heteronomia como origem de todos os princípios ilegítimos da moralidade, ou seja, como a própria imoralidade - no que reside também sua reação crítica ao empirismo de Hume que, no campo da moral, reduz a razão, nas famosas palavras do filósofo inglês, a "um escravo das paixões"11. 


\section{Conclusões}

No seu fundamento, a metafísica dos costumes kantiana elabora o conceito de moralidade pura e universal pondo sua base na autonomia da vontade pura. Entretanto, para se chegar à consolidação da aspiração da vontade guiada pelo imperativo categórico no esteio da autonomia, e tendo estes como lei universal, Kant admite um uso sintético da razão pura prática rumo ao conceito de liberdade enquanto chave de explicação da própria autonomia da vontade. Neste instante, irá se iniciar a transição - terceira e última seção da Grundlegung zur Metaphysik der Sitte - da metafísica dos costumes para a crítica da razão prática pura. Aqui, o conceito de liberdade irá fundamentar a autonomia da vontade como legisladora de si mesma guiada pelas leis morais universais; todo e qualquer recurso a Deus para estabelecer a boa vontade ou as leis morais está completamente rejeitado.

O ser humano então estará dividido entre aqueles dois mundos explanados por Kant em sua aula inaugural, conforme citamos inicialmente reiteramos: o mundo sensível e o mundo inteligível. Habitando unicamente o primeiro, a vontade estará determinada por leis naturais a partir dos objetos do desejo (heteronomia); enquanto que participando do segundo, o indivíduo será guiado por leis morais universais e livres dos interesses egoístas e impulsos irracionais. Neste mundo inteligível, o ser humano só poderá ser livre quando dono de uma vontade verdadeiramente autônoma (autonomia) com relação aos desejos e paixões. A liberdade então se põe como autonomia da boa vontade segundo princípios que fundamentam o dever em si mesmo, desvelando pela razão reabilitada enquanto capacidade de agir racionalmente como sujeitos realmente donos das suas escolhas. Portanto, trata-se de uma filosofia prática na medida "em que não temos de determinar os princípios do que acontece mas sim as leis do que deve acontecer, mesmo que nunca aconteça, quer dizer, leis objetivas práticas" (Kant, 1974, p. 228). E por leis objetivas práticas, Kant define "a relação de uma vontade consigo mesma enquanto essa vontade se determina pela razão" (Ibidem). Essa vontade autônoma é aquela que se submete à lei moral encontrada em si mesma, lei esta que define a sua concepção de liberdade como verdadeira felicidade. E para Kant, a felicidade de ser livre é o dever que se impõe a todos os seres humanos enquanto valor moral universal.

Permita-nos o leitor concluir estas notas retornando à origem de todo o dilema kantiano, assim como iniciamos este texto ao nos referir à provocação do filósofo inglês David Hume, que fez frente à toda tradição racionalista com seu implacável ceticismo. Ao que parece a afronta humeana marcou o pensamento de Kant, pelo que identificamos na sua reação assentada justamente no complexo arco teórico do seu projeto de crítica da razão e da própria 
modernidade. Entrementes, o alvo principal dessa crítica foi oferecer a defesa da liberdade e da moralidade, e assim fazendo preservar a perspectiva do lluminismo, pois talvez, pior do que aceitar a falência do racionalismo, seria sucumbir ao empirismo e seus efeitos, algo que jamais admitiu. Em suma, se "o sono da razão produz monstros", como alertou Goya, que diremos pois do seu despertar?

\section{Referências}

ALLAN POE, Edgar. O demônio da perversidade. In: Assassinatos na Rua Morgue e outras histórias. $-1^{\text {a }}$. Ed. - São Paulo : Mediafashion, 2016, p. 5-12 (Coleção Folha. Grandes nomes da literatura ; v. 11), p. 8.

BUCHANAN, Ian. Dictionary of Critical Theory. Oxford University Press Inc., New York, 2010.

DUDLEY, Will. Idealismo alemão. Tradução de Jacques A. Wainberg. Petrópolis, RJ : Vozes, 2013. - (Série Pensamento Moderno).

GOETHE, Johann Wolfang von. Gedichte - Herausgeben und kommentiert von Erich Trunz. München, Verlag C. H. Beck, 2007 (Jubiläumausgabe).

HUME, David. Tratado da natureza humana: uma tentativa de introduzir o método experimental de raciocínio nos assuntos morais. Tradução Déborah Danowski. - São Paulo: Editora UNESP: Imprensa Oficial do Estado, 2001.

KANT, Immanuel. Crítica da Razão Pura. Título original: Kritik der reinen Vernunft. In: KANT, 1ª . edição, Abril S.A. Cultural e Industrial, São Paulo, 1974 (Coleção Os Pensadores, Vol. XXV).

, Immanuel. Fundamentação da Metafísica dos Costumes. Título original: Grundlegung zur Metaphysik der Sitten. In: KANT, 1a. edição, Abril S.A. Cultural e Industrial, São Paulo, 1974 (Coleção Os Pensadores, Vol. XXV).

, Immanuel. Crítica da Razão Prática. Título Original: Kritik der Praktischen Vernunft. São Paulo, Editora Martin Claret, 2003a.

Immanuel. Fundamentação da Metafísica dos Costumes e Outros Escritos. Título Original: Grundlegung zur Metaphysik der Sitten. São Paulo, 
Editora Martin Claret, 2003b.

RUSSEL, Bertrand. História da Filosofia Ocidental. Título Original: History of Western Philosophy. Tradução: Brenno Silveira. 3a. edição. São Paulo, Companhia Editora Nacional, 1968.

\section{SCHOPENHAUER, Arthur. Crítica da filosofia kantiana. In: Schopenhauer - Vida e Obra. São Paulo, Editora Nova Cultural, 1999 (Coleção Os Pensadores).}

\footnotetext{
${ }^{1}$ Versão (inédita) revista e ampliada do breve ensaio "Vontade e moralidade na concepção de liberdade em Kant"; do mesmo autor; publicado na Revista Philipeia: https://revistaphilipeia.com/2016/10/24/filosofia/ . Agradecemos ao apoio da CAPES em proporcionar - por meio do estágio doutoral na Alemanha (PDSE) - os avanços necessários ao desenvolvimento dessa revisão a ampliação supramencionada do ensaio inicial, resultando neste artigo bem mais completo, e inédito.

${ }^{2}$ Cf. KANT, 2003a, p. 176 (Perfil biográfico).

${ }^{3} \mathrm{Cf}$. "His influence is so great, European philosophy is generally divided into pre-Kantian and post-Kantian school of thought" (BUCHANAN, 2010, p. 266).

4 Segundo Bertrand Russel, em sua História da Filosofia Ocidental, foi a Investigação Sobre o Conhecimento Humano "que despertou Kant de suas 'modôrras dogmáticas'; este parece não ter conhecido o Tratado [da Natureza Humana]" (RUSSEL, 1968, p. 201, grifo meu) - neste ensaio, mesmo que de passagem e em caráter secundário, confrontamos nossa leitura de Kant com o Tratado da Natureza Humana, tendo em vista que a obra a que se refere Russel quanto ao despertar de Kant se tratou de uma espécie de reformulação parcial deste último.

5 Will Dudley é professor-associado de Filosofia no William College, Massachusetts, EUA; e é autor da obra Idealismo Alemão (2013).

${ }^{6}$ E complementa Hume (Idem): "[...] temos de provar que essa conexão é tão necessária que deve ter lugar e exercer sua influência em toda mente bem intencionada, ainda que a diferença entre essas mentes seja, sob outros aspectos, imensa e até infinita".

${ }^{7}$ Em livre tradução do autor deste artigo: "Nada conheço sob o sol / que seja mais pobre do que os Deuses."

${ }^{8}$ Poema de Goethe no qual Prometeu desafia e reclama contra os deuses, em alusão à alegoria grega que se tornou ícone mitológico na representação do espírito filosófico que a tudo questiona e critica; a exemplo da postura assumida por Kant em sua Crítica da Razão Pura. Cf. GOETHE, 2007, p. 44-46.

${ }^{9}$ Dudley explica que "A iniciativa copernicana de Kant foi rejeitar a hipótese de que o sujeito precisa conformar o objeto em favor da hipótese de que o objeto precisa adequar-se ao sujeito. Se este fosse o caso, então a metafísica seria possível. Seria conhecido de todos os objetos que eles precisam ter certos traços necessários para que possam ser experienciados pelo sujeito. Estas características se aplicariam necessária e universalmente então aos objetos da experiência, e o conhecimento de tais características se qualificaria como metafísico. Nesta hipótese, portanto, a possibilidade de conhecimento metafísico seria preservada, mas a metafísica teria que ser conduzida de uma forma radicalmente nova" (2013, p. 32).

${ }_{10}$ O que se põe de acordo com a própria concepção de conhecimento transcendental na Crítica da Razão Pura, quando trata Da lógica transcendental (KANT, 1974, p. 59): "[...] transcendental deve denominar-se, não cada conhecimento a priori, mas somente aquele pelo qual conhecemos, que e de que modo certas representações (intuições ou conceitos) são empregadas ou são possíveis unicamente a priori (isto é, a possibilidade do conhecimento ou o uso do mesmo a priori). [...] transcendental podem chamar-se apenas o conhecimento de que estas representações não são de origem empírica e a possibilidade pela qual elas podem relacionar-se a priori com objetos da experiência".

${ }^{11}$ Cf. Dudley, 2013, p. 24.
} 